\title{
AN INTENSIVE ALPINE CLIMBING EXPEDITION AND ITS INFLUENCE ON SOME ANTHROPOMETRIC MEASUREMENTS
}

\author{
S. J. BAKER MSc., (H.Biol.), D.L.C. \\ Senior Lecturer, Department of Outdoor Education, \\ Normal College, Bangor, Gwynedd
}

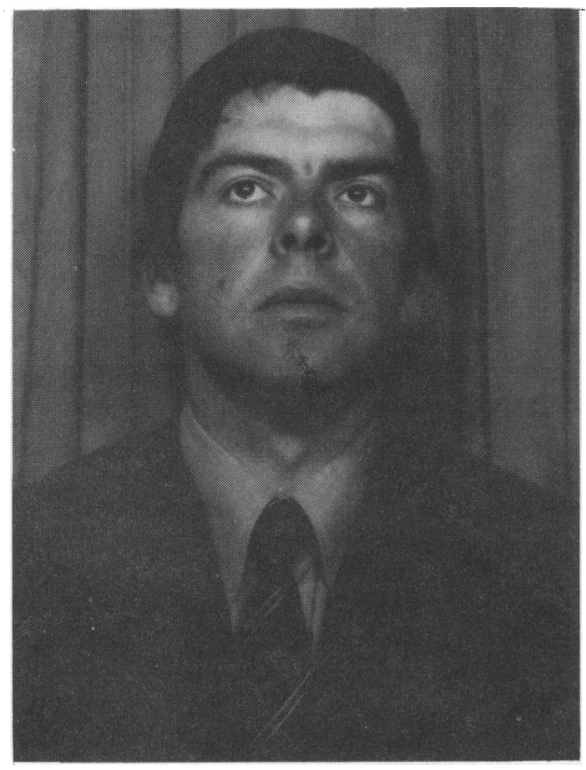
\begin{abstract}
returned home. taken on session one.

\section{INTRODUCTION}

Vigorous physical activity has a direct influence on body weight and composition. Keys 1953 has illustrated that there was a proportional change in body fat and muscle mass which resulted from vigorous muscular exercise. Many researchers have confirmed the findings of Keys (Dempsey, 1964; Novak, 1966) while others have shown that the ratio of lean body mass to absolute body fat is higher in physically active individuals and lower in the sedentary (Boileau, Buskirk, Horstman, Mendez and Nickolas, 1971).
\end{abstract}

ABSTRACT

The effects of an intensive 4 week Alpine climbing expedition on percentage body fat, absolute body fat and lean body mass was investigated in 14 adult male students. Anthropometric measures were taken on two occasions during the training period prior to the expedition, twice during the expedition and finally eight weeks after the expedition had

There was a $3 \%$ reduction in percentage body fat between the first testing occasion and the fourth taken towards the end of the expedition. Over the same interval there was a mean reduction of $2.6 \mathrm{~kg}$ in absolute body fat and a reduction in lean body mass of $2.47 \mathrm{~kg}$. All three criterion mean values on the final testing session returned to or exceeded those

The findings of this study indicate that a programme of vigorous activity has a profound effect on body fat values.

\section{PROCEDURE}

Fourteen healthy male students between the ages of 20 and 31 years with varying body builds and of whom all were pursuing a teacher training course in Outdoor
Education were taken to the French High Alps as a concluding expedition to their course. Preparations for the expedition began fifteen weeks prior to the departure date, and part of this preparation included a detailed analysis of the expedition work load (known from previous years) and a strong recommendation that a fitness programme be embarked upon immediately albeit self motivated.

The nature of the activity once in the Alps involved each individual carrying loads of between $15 \mathrm{~kg}$ and 20 $\mathrm{kg}$ for walks of between two to five hours with rises in altitude of $1200-1500$ metres.

In addition, long climbs lasting up to 18 hours and involving a total height change (ascent + descent) of 6000 metres, followed on subsequent days. Throughout the four-weeks of the expedition activity fell into periods of three day blocks. Day 1 involved a long walk to a mountain hut or bivouac site; day 2 involved a long climb on rock ice or both, finishing at the same or another mountain hut; day 3 involved another short 
climb followed by a descent to base camp at 1000 metres. The following day was spent resting.

A typical Alpine day started at 3 a.m. with a breakfast of cereal or porridge which many individuals found difficult to face at this early hour. The party then departed from their refuge at 4 a.m. in an attempt to reach the base of their climb by first light. It was not uncommon for temperatures to be as low as $-10 \mathrm{C}$ at this time. Cold effects were further accentuated by a moderate wind chill factor on several occasions but these tended to be less common at this time of the year (mid July).

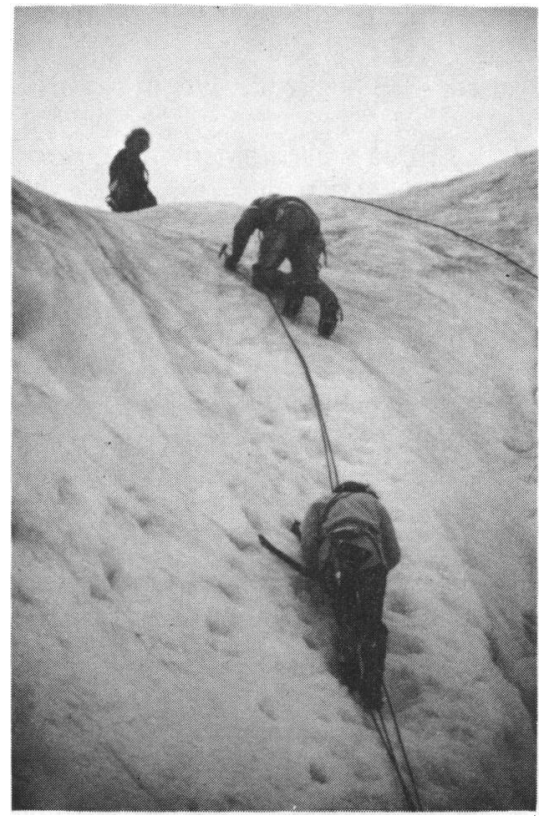

Fig. 1. Ice technique: Dauphind Alps.

Early starts were essential so that glaciers could be crossed while frozen hard, and snow and ice gullies could be climbed before the suns' fierce thaw action took effect. The midday heat was an environmental hazard equal to that of low temperatures. Snow glare, sun-burn and excessive sweating were to be avoided at all costs. In addition to the aforementioned discomforts those associated with acclimatization in the form of headaches, vomiting and breathlessness often make the experiences of the novice alpinist anything but pleasant.

\section{EXPEDITION FOOD}

At all times during the expedition food was plentiful. Many individuals chose to carry lighter dehydrated food during the climbing periods and return to fresh food at base camp. A typical daily climbing ration for four men is shown in Table 1.
TABLE I

Energy values of a four man pack per day

12 oz Porridge

10 oz dried fruit

16 oz dried milk

16 oz sugar

25 oz biscuits

10 oz sweets

4 oz dried soup

30 oz tinned meat

8 oz dried veg

12 oz rice

16 oz jam

8 oz margarine
K.cals

1380

550

1488

1792

3075

1500

320

1860

48

1224

1184

1868

Total for FOUR men $=16289$

$=$

4072

kcals/

man

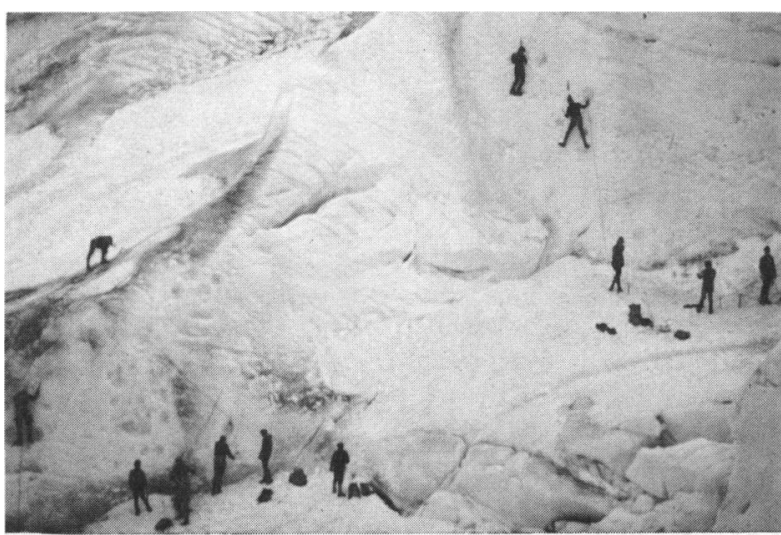

Fig. 2. École de glace.

\section{ENERGY VALUES}

Although there is an important psychological com? ponent to be considered in designing an expedition diet? it is reasonably straightforward to supply adequaten energy foods from simple calculations. Walking at $4 \mathrm{mph}$, requires $240 \mathrm{Kcals} / \mathrm{hr}$ (Green 1966) this approximates to. walking with a pack at $3 \mathrm{mph}$ over rough terrain $=140 \mathrm{w}$ $\mathrm{Kcals} / \mathrm{mile}$. A formula commonly used for predictinge total kilocalories for height gain =

Height climbed $(\mathrm{ft}) \times$ total body pack mass $\times 3.2389 \times 10 \stackrel{\text { 勇 }}{9}$

By substituting into this formula data from thङ present expedition, on only two occasions did energ $\vec{D}$ expenditure exceeed $4072 \mathrm{Kcals}$ - the mean value of the expedition food packs. The excess on both occasions was in the region of only $1000 \mathrm{Kcals}$. 
There is little doubt that the work load involved in the alpine course was heavy and demanding. It was equally obvious that a high level of pre-expedition fitness would be beneficial and to some extent essential for students and staff. Although students were advised to undertake a progressive programme of mountain activity prior to the expedition, culminating in long days involving considerable height gains, no attempt was made to enforce such a programme.

Data were collected on body weight had subcutaneous fat values before, during and after the expedition had finished.

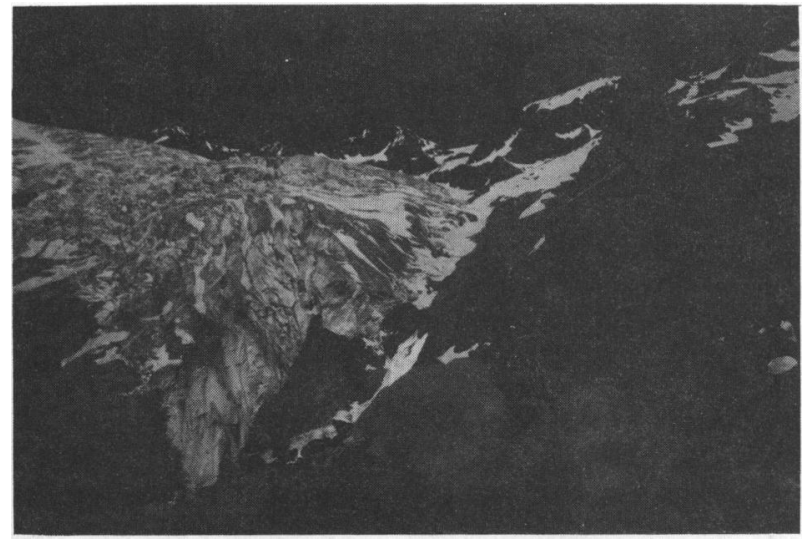

Fig. 3. Pelvous refuge.

\section{METHOD}

On five occasions during a total period of $\mathbf{3 0}$ weeks, body weight and skinfold thicknesses at four sites were recorded. The first two occasions preceded the expedition, the following two occasions were during the four week expedition period and the final measurements were taken eight weeks after the group returned home.

All measurements were taken by the same investigator. Skinfold thicknesses were taken with a Harpenden Skinfold Caliper which had a constant jaw pressure of $10 \mathrm{gm} / \mathrm{sq} . \mathrm{mm}$. The four sites used were as follows:

1. Biceps; with arm resting supinated, over the belly of the muscle at the same level as the triceps.

2. Triceps; with the arm hanging vertically relaxed, midway between the tip of the acromion and the olecranon process; and directly in line with the olecranon process.

3. Subscapular; under the inferior angle of the scapula; the fold pointing slightly downwards and outwards.

4. Suprailiac; $1 \mathrm{~cm}$ above and $2 \mathrm{~cm}$ medial to the anterior superior iliac spine.
All body weights $(\mathrm{kg})$ were taken with the same set of clinical scales.

Percentage body fats, absolute fats and lead body masses were calculated from the data according to the method of Durnin and Rahaman 1976; and Siri, 1956.

$$
\begin{aligned}
D & =1.1610-.0632 x \\
\text { where } D & =\text { density } \\
X & =\log \Sigma \text { fats } \\
\% \text { body fat }= & 4.95-4.5 \times 100
\end{aligned}
$$

Absolute body fat $(\mathrm{kg}): \mathrm{ABF}=\begin{gathered}\text { Nude body weight } x \% \text { fat } \\ 100\end{gathered}$

Lean body mass : $L B M=$ Nude weight $-A B F$.

Each of the three measurements criterion were illustrated and treated statistically using a Sandlers $A$ test.

The null hypothesis $\mathrm{H}_{0}$ that there was no difference in body measurements taken before and during the expedition was tested against the alternative hypothesis $\mathrm{H}_{1}$ which states that there was a difference between body measurements taken before and those taken during the expedition.

\section{RESULTS}

Means and standard deviations of percentage body fats, absolute body fat and lean body mass are shown in Table II.

TABLE II:

Showing \% body fat (\%BF), absolute body fat (ABF), and lean body mass (LBM) for 14 subjects measured on five occasions (mean \pm standard deviation)

\begin{tabular}{llllll}
\multicolumn{5}{c}{ OCCASIONS } \\
\% BF & A & B & C & D & E \\
& 11.20 & 10.9 & 9.47 & 8.24 & 10.77 \\
& \pm 1.5 & \pm 1.73 & \pm 1.69 & \pm 1.6 & \pm 1.62 \\
ABF & 6.81 & 6.23 & 4.21 & 4.21 & 7.82 \\
& \pm 1.93 & \pm 1.81 & \pm 1.99 & \pm 1.76 & \pm 1.84 \\
LBM & 61.9 & 60.82 & 61.7 & 59.43 & 64.6 \\
& \pm 14.9 & \pm 15.01 & \pm 14.62 & \pm 15.31 & \pm 14.3
\end{tabular}

It can be seen from Table II that there is only a slight reduction in \% BF (.3\%) between occasions $A$ and $B$, that is in the period preceding the alpine course when subject training was self motivated. This trend is also seen in the difference between $A B F$ values on occasion $A$ and $B(.58 \mathrm{~kg})$. The lowest values in the means of all 
three measurement criteria are seen on occasion $D(\% B F$ $=8.24 ; A B F=4.21 \mathrm{~kg}, L B M=59.43)$. This result is expected since measurements were taken towards the end of the expedition after a period of intensive activity.

Table II shows also that the mean scores of all three variables observed on occasion $E$ have reverted back to or have even exceeded those recorded on occasion $A$. This trend suggests that the general level of activity between occasions $D$ and $E$ was severely curtailed.

However, it is useful to test the significance of the observed changes and this was done by employing a Sandlers A statistic. For the purpose of this analysis a comparison between the pooled scores of occasion $A$ and $B$ with the pooled scores of occasion $C$ and $D$ was made. Since the scores on occasion $E$ were intended to illustrate whether a high level of physical fitness had been maintained over a summer vacation where activity was self motivated, these scores were not incorporated into the statistical analysis.

The results of this before and after effect are shown in Table III. It can be seen that Sandlers A values for all three tests were less than the critical values and thus were significant. These results confirm the observations that there was a significant difference between antropometric measurements taken before leaving for the Alpine course and near the end of the expedition.

\section{TABLE III}

Showing the results of Sandlers A statistics on the three test criterion.

$$
\alpha=.01
$$

Critical values

Sandlers A values

$\%$ fat

.176

.089

Absolute body fat

.176

.104

Lean body mass

.176

.108

\section{DISCUSSION}

The students who were involved in the Alpine climbing expedition had selected outdoor activities as their vocation. Many were experienced climbers and two of these had been involved in expeditions to other high mountain ranges. All were aware of the inherent work load of the trip although perhaps few had hitherto experienced anything similar.

The results of the study have shown clearly that significant amounts of body fat were utilized during the expedition. However there are a number of factors which must be considered in addition to the sheer work load involved.

There was no doubt amongst the students that the quality of the food throughout the alpine course was very high. In addition to the food taken from Britain ${ }_{3}^{\frac{5}{3}}$ fresh supplies supplemented the base camp menum continually. There was certainly enough food available? since much was returned to Britain. This could not be attributed to the food being unappetizing since the whole alpine menu was planned following a detaileof discussion about the likes and dislikes of the group members.

On arrival at base camp the entire store of food wass distributed to tent units. From this point onwards each $\overrightarrow{0}$ climbing party was responsible for its own menu both in base camp and on the mountain. There is the possibility. that groups decided to carry little food during climbing $\mathrm{O}$. periods although this was not apparent from casuaks? observations. However, as both lean body mass as well as body fat decreased during the expedition phase, the climbers must have been in negative energy balance despite the high levels of food supplied. Unconsumed wastage may be a factor.

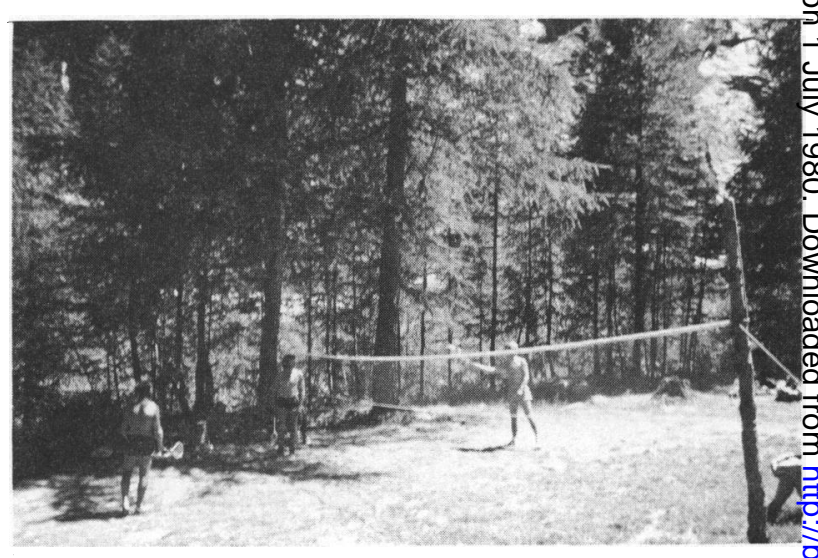

Fig. 4. Base camp: rest day.

A small number of students suffered from altitude sickness during the early stages of the trip and this may? have reduced their food intake temporarily. However? during the early stages the pace and work load was deliberately reduced to allow gradual acclimatization

Throughout the course a small number of individuals suffered from mild attacks of dysentry but in only one case was the attack prolonged (seven days). VictimR remained in base camp and were encouraged to maintainw a high level of liquid intake.

Attention was constantly directed to the importanceह of salt and an adequate if not (apparently) superfluous liquid consumption while on the hill. Over $80 \%$ of the alpine course was spent in uninterrupted sunshine⿻ with temperatures exceeding $30^{\circ} \mathrm{C}$.

The novice alpinist experiences initial difficulty in 
judging an economical pace. However many students decided eventually to forfeit a relaxed and steady walk to the base of a route in return for beating the opposition and getting there first. On many routes it was not uncommon to see a dozen parties or more. Many of these mountaineers are themselves novices led by a guide and the care in climbing and preventing debris from falling on parties below is often wanting. Therefore one must seriously consider a somewhat speedier approach to the base of the route to be first as an additional overall safety factor.

A first alpine expedition is awe inspiring. The magnitude of the towering peaks often can have psychological undertones. It is not uncommon for individuals to experience a fear of leaving the security of base camp. However in a group of physically active males, collective competitive pressures may conceal in some individuals misgivings about enthusiastic participation. Although none of these symptoms were detected within the group of students, in some they may have been present and had detrimental effects.

\section{SUMMARY}

An attempt has been made to highlight some of the salient factors which might have contributed during the alpine course to the observed changes in anthropometic measures. A choice of good food was available to replenish high energy expenditure through intense activity. The environmental conditions in which this activity took place ranged from low night time temperatures of $-10^{\circ} \mathrm{C}$ to mid day temperatures in excess of $30^{\circ} \mathrm{C}$.

Although the nature of the expedition programme was determined by staff, it was accepted unquestionably by the group and for this they must be congratulated. Notwithstanding the hard earned fitness achieved during the expedition few students opted for the level of activity in the ensuing months to maintain it.

This study serves to show the approximate amount of body fat that even a relatively fit mountaineer might lose during an intensive alpine climbing trip.

\section{REFERENCES}

Åstrand, P., Rodahl, K., 1970, Textbook of Work Physiology. McGraw Hill, New York \& London.

Boileau, R. A., Buskirk, E. R., Horstman, D. H., Mendez, J., Nickolas, W. C., 1971, “Body composition changes in obese and lean men during physical conditioning." Medicine and Science in Sport, 3: 183-89.

Dempsey, J. A., 1964, "Anthropometric observations on obese and non obese young men undergoing a programme of vigorous physical activity." Res.Quart. 35: 275-287.

Durnin, J. V. G. A., Rahaman, M. M., 1967, "The assessment of fat in the human body from measurements of skinfold thickness." Brit.Journal Nutrition 21: 681-9.

Green, J. H., 1966, An introduction to Human Physiology.

Haker, A., Runyon, P. R., 1972, General Statistics, Addison-Wesley, London.

Key, A., 1953, “Body fat in adult man." Physiological Review 33: 245-325.

Norvak, L. P., 1966, "Physical activity and body composition of adolescent boys." J.Amer.Med.Assoc. 147: 891-893.

Siri, W. E., 1956, "In Advances in Biological and Medical Physics." J. H. Lawrence and C. A. Tobias, Academic Press. London and New York. 